\title{
A one-month study of the zooplankton community at a fixed station in the Ligurian Sea: the potential impact of the species composition on the mineralization of organic matter
}

\author{
L. Mousseau ${ }^{1,2}$, D. Lefevre ${ }^{3}$, F. Narcy ${ }^{1,2}$, P. Nival ${ }^{1,2}$, and V. Andersen ${ }^{1,2}$ \\ ${ }^{1}$ UPMC Université Paris 06, UMR 7093, Laboratoire d'Océanologie de Villefranche, 06230 \\ Villefranche sur mer, France \\ ${ }^{2}$ CNRS, UMR 7093, LOV, 06230 Villefranche sur mer, France \\ ${ }^{3}$ LMGEM UMR CNRS 6117, France \\ Received: 4 November 2008 - Accepted: 1 December 2008 - Published: 16 January 2009 \\ Correspondence to: L. Mousseau (laure.mousseau@obs-vlfr.fr) \\ Published by Copernicus Publications on behalf of the European Geosciences Union.
}

995

\begin{abstract}
The cruise project was designed to study temporal variations of the ecosystem during the summer-autumn transition and focused on the part played by zooplankton as top-down controllers, and the relative importance of top-down versus bottom-up con-

5 trols. Zooplankton should play a key role both in the vertical transfer of particulate organic matter and in the mineralisation of organic matter. Although the importance of species diversity is well recognized, the impact of diversity on carbon fluxes is rarely considered. Trophic roles of zooplankton range from strict herbivory to strict carnivory, with all possible combinations (i.e. omnivory) between these two extremes. Feeding 10 strategies are also very diverse, for example, active predators, passive filter feeders or suspension feeders co-exist (Bamstedt at al., 2000). As the metabolic cost of these different trophic roles and ways of feeding should be different, a physiological diversity must be considered in any assessment of the role of zooplankton in the flux of organic matter (e.g. Longhurts and Harrison, 1989). At a minimum,, species and functional 15 diversities contribute to the diversity of exported organic matter (Steinberg et al., 2000; Madin et al., 2001). Fecal pellets, the organic matter egested by zooplankton, differ in form, size and weight, and hence in their sedimentation and degradation rates (Turner, 2002). The downward flux of organic matter thus depends on not only on physical and chemical processes but also on biological variables.

20 The area sampled, located in the central part of the Ligurian Sea is next to the DYFAMED site, a time-series station monthly monitored for several years now. The zone is considered to be oligotrophic and protected from strong advective processes (Andersen and Prieur, 2000). The two cruises DYNAmic of the rapid PROCess (DYNAPROC 1 in May 1995 and DYNAPROC 2, the present study) were devoted to factors control25 ling the vertical flux of matter on short time scales. The aim of the work presented here was to estimate, at a fixed station in the Ligurian Sea (NW Mediterranean Sea),the impact of zooplankton on organic matter fluxes. We determined the species composition and then for the dominant species of the community, we estimated rates of, oxygen
\end{abstract}


consumption, carbon dioxide production and ammonium excretion. Our sampling period, the summer-autumn transition featuring strong wind events, offered contrasting situations for primary and export production (Marty et al., 2008). We thus have the opportunity to estimate how the zooplankton, from a species-specific point of view, react

5 to these changes.

\section{Material and methods}

\subsection{Sampling site}

The Dynaproc 2 cruise took place in autumn 2004, from 14 September to 17 October, in the central part of the Ligurian Sea, close to the long-term series DYFAMED site

10 (Fig. 1). The purpose of the cruise was to follow the transition from a summer oligotrophic situation to an autumn mesotrophic conditions, from a stratified water column to a mixed one. The sampling site $\left(43^{\circ} 25 \mathrm{~N}, 8^{\circ} 00 \mathrm{E}\right)$ was setting according to the water masses identified by CTD profiles along a transect from coast to offshore waters. Moreover, a grid of 16 stations around the central site was sampled three times during the cruise to better describe the water mass movements around the site.

\subsection{Mesozooplankton sampling strategy}

Zooplankton were sampled with three types of nets. Taxonomy, biomass and physiology were determined for small organisms (ca. $200 \mu \mathrm{M}$ ) using organisms captured with vertical WPII nets $(50 \mathrm{~cm}$ diameter, $200 \mu \mathrm{m}$ mesh size) and horizontal BONGO net

20 (50 cm diameter, 200 and $100 \mu \mathrm{m}$ mesh size), and for the larger species (ca. $500 \mu \mathrm{M})$ with a BIONESS multinet (1 square meter, $500 \mu \mathrm{m}$ mesh size). Within the 4-week cruise, a high frequency sampling was carried out for 4 cycles: 17-22 September (C1), 25-30 September (C2), 3-8 October (C3), 10-16 October (C4). The WPII nets were deployed at midday and midnight whereas the BIONESS and BONGO were only used during night samplings.

Three WPII nets were mounted together in order to get three samples at the same time, aiming to reduce the variability due to the patchiness distribution of zooplankton. Vertical hauls from $200 \mathrm{~m}$ to surface, or $500 \mathrm{~m}$ to surface were conducted at midday and midnight. Material from two nets was used to for biomass estimates (dry weight) 5 and the third one for organism abundance and taxonomic identification.

The multinet was operated obliquely within the $250 \mathrm{~m}$ water column. A BIONESS $(0-250 \mathrm{~m})$ haul was specifically dedicated to taxonomy and the others for physiology. To obtain organisms in good conditions for physiological rate estimates, the tows lasted ca. $5 \mathrm{mns}$ for each sampling depth. The BONGO net was towed drifting within the first $1050 \mathrm{~m}$ for 5 to $10 \mathrm{mns}$. The cod-end were specially adapted (large volume $5 \mathrm{dm}^{-3}$ ) to avoid injuring the organisms.

\subsection{Integrated biomass}

The cod-end contents of two WPII were poured in a beaker. The organisms were then filtered onto pre-weighed filters $(200 \mu \mathrm{m}$ mesh size), rinsed with isotonic ammonium

15 formate and then rapidly frozen and kept frozen $\left(-20^{\circ} \mathrm{C}\right)$ until processing back at the laboratory. There, each filter were dried $48 \mathrm{~h}$ at $60^{\circ} \mathrm{C}$ (in Harris et al., 2000) and weighed and a Sartorius balance (accuracy of $0.01 \mathrm{mg}$ ). Fish larvae were picked out of the samples as non-planktonic organisms. Biomass was expressed as dry weight $\left(\mathrm{g} \mathrm{m}^{-2}\right)$. As two vertical hauls were made $(0-200 \mathrm{~m}$ and $0-500 \mathrm{~m})$, we can have an 20 idea of the potential nycthemeral migrations.

\subsection{Taxonomy}

The samples for species identification were preserved in $4 \%$ buffered formaldehyde seawater solution for further species determination. Samples for taxonomic determination and abundance were processed using a dissecting microscope. Identification was done to species level when possible. The third net was not available during $\mathrm{C} 1$, frozen samples were used for taxonomic determination, the filter was gently thawed in 
a beaker at room temperature. The identification was less accurate because of the impact freezing on organic tissues, especially for the gelatinous organisms. Even if they are less valuable, these data were kept as indicative of at least a minimal abundance.

\subsection{Physiological measurements}

5 Experiments were conducted on night samples, as we reasonably postulated that plankton organisms migrate in surface waters and are more active during night than day (Kleppel et al., 1985). The collected samples were gently diluted into a large volume of seawater. The containers were then put in the cold room (seawater temperature $17^{\circ} \mathrm{C}$ ) at dark. We sorted immediately the organisms under dim light to species,

10 and isolated them in filtered seawater $(0.2 \mu \mathrm{m})$ at room temperature for less than one hour. Groups of organisms of the same species were then transferred into incubation chambers filled with oxygenated filtered seawater $(0.2 \mu \mathrm{m})$. Volumes of the incubations and densities were adapted to the size of the organisms. For copepods, incubation chambers were usually $50 \mathrm{~cm}^{3}$ for 10 individuals; for larger species (pteropods, 15 chaetognaths, euphausiids), incubation volume ranged from $250 \mathrm{~cm}^{3}$ to 1 liter with a final density of 1 to ca. 15 ind $\mathrm{dm}^{-3}$. The incubations ran for $12-15 \mathrm{~h}$ at $17^{\circ} \mathrm{C}$ in darkness. Control chambers filled with filtered seawater without zooplankton were also incubated to check for possible changes in oxygen concentrations.

Oxygen and $\mathrm{CO}_{2}$ measurements were conducted as described in Mayzaud et 20 al. (2005). Briefly, oxygen concentrations were analysed with a Strathkelvin oxymeter equipped with a Clarke-type electrode. $\mathrm{CO}_{2}$ concentrations were analysed by colorometric titration (Johnson et al., 1987). The difference between initial and end values corrected by the control value gave the oxygen consumption and the carbon dioxide production during the incubation time. At the end of the incubations, animals were

25 stored in buffered formalin for later confirmation of the species and size measurements.

Ammonium concentration of the incubated water $\left(a 40 \mathrm{~cm}^{-3}\right.$ aliquot in a $50 \mathrm{~cm}^{-3}$ Schott bottle) was determined on board on a Turner Design TD-7OO fluorimeter (Holmes et al., 1999).

The respiratory quotient $\left(\mathrm{RQ}=\Delta \mathrm{CO}_{2} / \Delta \mathrm{O}_{2}\right)$ and the metabolic quotient $\left(\mathrm{MQ}=\Delta \mathrm{O}_{2} / \Delta \mathrm{NH}_{4}\right)$ were first calculated for each incubation, then a geometric mean was used to determine these quotients by species.

\section{Results}

5 2.1 Hydrological environment (Fig. 2; Andersen et al., 2008)

Briefly, the cruise started with a well-stratified water column (see Andersen et al., 2008, for a detailed description). The thermocline was ca. $25 \mathrm{~m}$, with temperature in the mixed layer ca. $20^{\circ} \mathrm{C}$. Some wind was registered, but not strong enough to mix the upper layer. Strong wind events from 11th of October initiated a de-stratification of the water column

10 and a decreasing of the temperature (below $18^{\circ} \mathrm{C}$ ) at the end of the cruise. This pattern suggests that the autumnal conditions were in progress.

Intrusions of low salinity waters originated from the coast were the outstanding events of this period and confirmed that the central part of the Ligurian Sea could be submitted to local lateral advection (Stewart et al., 2007). The first occurred from

15 21st to 30th September with salinity $<38.05$ between 15 and $75 \mathrm{~m}$ (LSW-1). The second intrusion, from 9 th to 12 th October, was restricted to the $20-40 \mathrm{~m}$ layer with salinity between 38.20-38.30 (LSW-2).

Time-depth distribution of the chlorophyll-a biomass exhibited a bimodal distribution at the beginning of the cruise (mid-September), with peak values at $50 \mathrm{~m}$ and $80 \mathrm{~m}$.

20 The deeper maxima disappeared quite quickly because it was supported by a high concentration of a diatom (Corethron cryophilum) that was in a senescent phase. The upper one persisted until the end of the cruise.

\subsection{Zooplankton integrated biomass (Fig. 3)}

Integrated biomass over the 0-200 $\mathrm{m}$ and 0-500 $\mathrm{m}$ water column showed some vari25 ability day after day, as well at day as at night (Fig. 3). In the 0-200 m layer, integrated 
biomass varied between 0.15 and $3.8 \mathrm{mgDW} . \mathrm{m}^{-2}$. The general trend exhibited an increase from 23 to 29 September, with maximum values on the 29th of September $\left(3.7 \mathrm{~g} \mathrm{~m}^{-2}\right.$ at night and $1.5 \mathrm{~g} \mathrm{~m}^{-2}$ during the day). The rest of the time, day values were $<1 \mathrm{~g} \mathrm{~m}^{-2}$ and night values $<2 \mathrm{~g} \mathrm{~m}^{-2}$. The observed values are in the range of

5 those measured in September and October 2001 and 2002 at the DYFAMED site (personal data). The integrated biomass in the $0-500 \mathrm{~m}$ layer ranged between $1.5-2 \mathrm{~g} \mathrm{~m}^{-2}$ overall during the cruise, with day and night values quite similar.

For both layers, night integrated biomass were generally higher than day ones $(p<0.001)$. In the $0-500 \mathrm{~m}$ layer, day concentrations were higher than those in the

$10 \quad 0-200 \mathrm{~m}$ layer whereas at night, both concentrations were equal or even higher in the 0-200 m layer (Fig. 3). This pattern could depict the movements of vertical migrants which occupied the upper layer at night, mainly for feeding (Dam et al., 1995). This is also coherent with the so-called deep scattering layer usually occurring around or below $500 \mathrm{~m}$. Peak values were registered on the 12th of October for both layers at 15 night ( 3.5 and $3 \mathrm{~g} \mathrm{~m}^{-2}$ respectively), date corresponding to a wind speed relax.

\subsection{Species composition}

The overall variations of the zooplankton groups are detailed in Raybaud et al. (2008). Here, we described more specifically and focus on the structure of the copepod and non-copepod communities of zooplankton in relation with the physiological measure-

20 ments to depict the change overtime in the impact of the major groups.

\subsubsection{WP II sampling}

The zooplankton community sampled with the WP II was dominated by the copepods, the dominant species being Clausocalanus sp. (ca. 20\%) closely followed by Oithona sp. (ca. 10\%), the main genera of the Oithonidae for the two legs. Calanoidae dom-

25 inated the copepod group (>80\%). The general trend of copepod abundance was a slight increase from 26th of September to 7th of October, with total abundance less

1001

during the first leg than during the second one. The total abundance of copepods was less than 100 ind $\mathrm{m}^{-3}$ for the whole period, except for the 26th of September and the 5 th of October where the abundance rose up to 234 and $133 \mathrm{ind} \mathrm{m}^{-3}$, respectively. These increases were largely Clausocalanus sp. but all genera increased. The peak value in

5 September occurred during the first intrusion of low salinity water. Interestingly, Pleuromamma sp. appeared from 26th of September to the end of the cruise, coincident with the intrusion of low salinity water (Fig. 4a, c).

The abundance of the non-copepod taxa was $<100$ ind $100 \mathrm{~m}^{-3}$ until the 26th of September, and then greatly increased up to 300 ind $100 \mathrm{~m}^{-3}$. For the first four sam10 pling days, the community was composed of several groups in small proportions $(<1 \%)$, whereas three main groups: siphonophors (mainly Agalma sp.), pteropods (Cavolinia inflexa and Clio pyramidata) and appendicularians represented more than $60 \%$ of the total community afterwards. The peak values were mainly due to occurrence of appendicularians. Noticeably, Agalma sp. and Clio pyramidata appeared as soon as the

15 26th of September and lasted until the end of the cruise. For Leg 1, non-copepod grouped under "others" (unidentified and <1\%) dominated, but we must keep in mind that the counting was based on frozen samples for the first leg and on preserved samples for the second leg. Thus, gelatinous organisms may have been destroyed and abundances underestimated (Fig. 4b, d).

\section{2.3.2 Multinet sampling}

Organisms bigger than $300 \mu \mathrm{m}$ were sampled with this net filtering a large volume of water. Three species of calanoida copepods dominated $(>60 \%)$ the copepod assemblage, Neocalanus gracilis being the more prevalent, and then Euchaeta sp. and Pleuromamma sp. The overall abundance was ca. $400 \mathrm{ind} \mathrm{m}^{-3}$ except of the 26 th

25 of September were maximum values reached $>1400$ ind $\mathrm{m}^{-3}$, during the input of low salinity water (Fig. 5a, c). This increase was mainly supported by a higher abundance of Neocalanus gracilis.

The non-copepod community was more abundant $\left(>150 \mathrm{ind}^{-3}\right)$ during the first leg 
than during the second one $\left(<150\right.$ ind $\left.\mathrm{m}^{-3}\right)$. The community was clearly dominated by the euphausiids (Nematoscelis megalops and Meganyctiphanes norvegica) for Leg 1 whereas pteropods (mainly Cavolinia sp.) or hyperiid (Vibilia armata) co-dominated during Leg 2. The 26th of September was also a particular date with a greater abun5 dance $\left(250 \mathrm{ind} \mathrm{m}^{-3}\right)$ than others sampling dates. Chaetognaths contributing to up to $22 \%$ to the community at this time (Fig. $5 b, d$ ).

\subsection{Physiological measurements}

\subsubsection{Metabolic and respiratory quotients}

As oxygen consumption, carbon dioxide release and ammonium excretion were si-

10 multaneously determined on the same incubated organisms, they were combined to determine the specific respiratory $\left(\mathrm{CO}_{2}\right.$ produced: $\mathrm{O}_{2}$ consumed) and metabolic quotients $\left(\mathrm{O}_{2}\right.$ consumed: $\mathrm{NH}_{4}$ excreted). Geometric mean and standard deviation were calculated for each experimental batch. At first sight, no trend appeared between the physiology of the organisms sampled during Leg 1 and Leg 2, whatever species considered (Fig. 6). Moreover, due to overlapping sd, we decided to pool together all data on a given species to obtain one quotient per species (Table 1).

$\mathrm{RQ}$ ranged between 0.73 for siphonophors (Chelophyes appendiculata) to 1.61 for chaetognaths (Sagitta sp.). The mean of $R Q$ values whatever species considered gave a value of 1.15, which is quite higher than the accepted one sets to 0.97 (Ikeda et al.,

20 2000) but closed to the one (1.31) estimated by Mayzaud et al. (2005) for a community dominated by large crustaceans and thaliaceans. The range of variations of MQ was between 8.02 (Vibilia armata) and 20.99 (Thysanopoda sp.). In our case, MQ was always less than 24 , indicating that the studied species metabolism was preferentially protein-based (Ikeda et al., 2000).

1003

\subsubsection{Carbon ingestion}

Under certain assumptions, ingestion rate can be calculated from respiration rates. Thus, an estimation of the minimum carbon requirements of zooplankton may be evaluated (Hernandez-Leon and Ikeda, 2005). These authors assume that carbon inges5 tion is 2.5 times the respiration rate expressed here in $\mu \mathrm{gC} \mathrm{ind} \mathrm{d}^{-1} \mathrm{~d}^{-1}$. Overall, on an individual base, estimates of carbon ingestion during Leg 2 were slightly higher than during Leg 1 for a given species (Fig. 7), except of Meganyctiphanes norvegica. The ingestion was of course linked to the size of the organisms, the bigger ones needing more carbon uptake to sustain their basal metabolism.

10 In order to determine the ingestion of the total community, we have multiplied the specific carbon ingestion by the abundance of the same species in the community for each sampling date. Small copepods sampled with the WPII net were not considered due to 1) their low abundance compared to these of bigger copepods, and 2) the lack of physiological data. To keep coherent with the species composition described above,

15 we worked with 3 groups of crustaceans ( 3 genera of copepods, 2 of euphausiids and one for amphipods), chaetognaths, 3 groups of gelatinous zooplankton (two genera of pteropod, one of siphonophor and appendicalarian). For appendicularians and $\mathrm{Ne}-$ matoscelis megalops, we used oxygen consumption from literature (Lombard et al., 2005; Raymont and Conover, 1961, respectively) and a RQ of 0.97 to estimate their 20 carbon ingestion.

The purpose of estimating overall pooled zooplankton ingestion rates was to compare the carbon demand of the entire zooplankton community to carbon supplied by primary production, ignoring the average trophic level (e.g., herbivore vs. carnivore) of the zooplankton. If this carbon demand is less than the primary production, this means

25 that the production of phytoplankton is enough to fuel the zooplankton ingestion. The total carbon demand by the zooplankton community (Fig. 8) was always lower than the primary production, estimated at $20-50 \%$ of the phytoplankton carbon production for Leg 1 and $<10 \%$ for Leg 2 . The maximum carbon demand ( $50 \%$ of primary production 
on the 20th and 26th of September and 35\% on the 14th of October) occurred when the abundance of euphausiids increased (Fig. 5). It is noticeable that the total carbon demand by zooplankton (Fig. 8) was higher in September $\left(60-120 \mathrm{mgC} \mathrm{d}^{-1}\right)$ than in October $\left(7-50 \mathrm{mgC} \mathrm{d}^{-1}\right)$. The maximum value on the 26 th of September reflected the 5 increase abundance of all zooplankton linked to the low salinity water input.

\section{Discussion}

The fixed station as near the DYFAMED site where a long time-series data of primary production show that the summer oligotrophy to autumn mesotrophy transition usually occurs between mid-September and mid-October. The 6 week DYNAPROC study was

10 programmed to follow the impact of (1) this switch from summer to autumn, and (2) wind stress events on the planktonic communities, from the bacteria up to the macrozooplankton. However, in 2004, the transition was delayed in time and just started at the end of the cruise. We were not able to track the effect of the seasonal transition on planktonic populations. However, two mains events occurred with the input of low 15 salinity water and some wind stress around the 12th of October.

\subsection{Zooplankton community species composition}

The intrusion of low salinity water in September lead to an increase abundance of copepods and non-copepods taxa regardless of size class. The main groups affected were the appendicularians, euphausiids and three species of copepods (Neocalanus gracilis, Clausocalanus sp. and Oithona sp.). Noticeably, the appearance of small noncopepod taxa (appendicularians, siphonophors and pteropods) was linked to this event whereas this was not observed for the larger ones. Raybaud et al. (2008) suggest that the advection of a distinct coastal water mass with its own zooplankton community occurred and that we sampled inside this water mass during its way through the sampling area.

The second episode of the intrusion of low salinity water had no obvious effect on the zooplankton community. At this time of the cruise, the forcing by strong wind events and the start of the seasonal de-stratification could have lowered the effect of the less salty water on the community.

5 The net we used to sample the smaller organisms (like Oithonidae), the WPII with a $200 \mu \mathrm{m}$ mesh size, was towed vertically, filtering about ca. $44 \mathrm{~m}^{-3}$. Comparatively, the multinet (BIONESS) explored a much greater volume $\left(>300 \mathrm{~m}^{-3}\right)$. This significant difference in filtered volumes could explain why the abundances of small copepods like Oithonidae and small calanoids were low compared to larger copepods sampled - with the BIONESS. As a result, we did not used the abundance of small organisms to compute the respiratory and metabolic quotients.

\subsection{Physiological data}

Values of $\mathrm{CO}_{2}$ production and related $\mathrm{RQ}$ are scarce in the literature and thus comparison with other data is difficult. In theory, the $R Q$ could range from 0.71 to 1 , depending 15 on the nutritive substrate used by the organisms (Ikeda et al., 2000). The muscular mass (hence activity) could also contribute to the RQ (Mayzaud et al., 2000). Our values of $R Q$ are $>1$, which is indicative of a metabolic substrate preferentially based on proteins and carbohydrates, rather than on lipids. These values are higher than those estimated by Mayzaud et al. (2000), particularly for the 3 species of copepods.

$20 \quad T$ The $M Q$ is more variable between species than the $R Q$. This ratio varies according to the metabolic substrate (Mayzaud et Conover, 1988) and indicates if the metabolism of the organism is rather based on lipids or proteins, the pivot value set at 24 (Ikeda et al., 2000). The present values $<24$, featuring a protein-based metabolism, are coherent with the $R Q$ simultaneously estimated. The present data for copepods are coherent 25 with those determined by Mayzaud (1973) for four species of copepods. 


\subsection{Carbon ingestion}

During the respiratory process, $\mathrm{CO}_{2}$ produced represents the minimal carbon demand by the organism, whatever its feeding regime (herbivorous, carnivorous or omnivorous). Reasonably, bigger species have an ingestion rate higher than the smaller ones,

5 which could explain the high percent carbon demand when euphausiids dominated the zooplankton community in September and October. Using our estimates of speciesspecific rates and abundances, we have estimated the total carbon demand of the whole zooplankton community (except of the smaller part, i.e. $<180 \mu \mathrm{m}$ ). Comparing these values with those of primary production (daily "carbon input" to the surface

10 layer), we observed that the primary production could have been sufficient by itself to sustain the zooplankton community. Zooplankton carbon ingestion represents no more than $10 \%$ (except of 26th of September where an increase in the abundance of Neocalanus gracilis, herbivorous, was observed) of the primary production. As less than $5 \%$ of primary production was estimated to be exported in deep waters (Marty et al.,

15 2008), ca. $80 \%$ of primary production remained available for the microbial pathways, microzooplankton then constituting the bulk of the secondary producers. This idea is reasonable within the context of oligotrophy at the sampling site where regenerated production dominated (Marty et al., 2008) and agrees with the results presented in Hernandez-Leon and Ikeda (2005).

As no significant changes in species composition was observed between Leg1 and Leg 2, the observed slightly lower carbon ingestion during Leg 2 could be a result of a decrease in the carbon demand (e.g. a weak grazing pressure) induced by the mixing of the water column. A higher ingestion during Leg 1 is coherent with high fluxes measured within the sediment traps (Marty et al., 2008)

1007

\section{Conclusions}

This study underlines the interest of determining the different physiological rates according to the species or group considered. To our knowledge, it is the first time that simultaneous measurements of oxygen consumption, carbon dioxide release and am5 monium excretion have been made with in the field, and hence specific physiological ratios of wild individuals computed. This approach will bring a new insight into models of pelagic ecosystems, allowing a more reasonable, data-based, depiction of the zooplankton box.

Acknowledgements. This study was part of the PECHE project; financial support was provided 10 by the INSU-CNRS, through the PROOF program (JGOFS-France). We thank the chief scientist, Valérie Andersen who organized the DYNAPROC 2 program, and the crew of the R/V Thalassa for field operations. We thank Nicole Garcia for her help at sea for the ammonium measurements and to have kindly provide primary production data. We thank Alexandra Gubanova, Denis Altukhov and Serguey Khvorov for their contribution with the samples 15 identification and counting. This work is dedicated to Valérie, our friend and colleague, who passed away prematurely in March 2007.

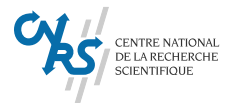

INSU The publication of this article is financed by CNRS-INSU.

20

Andersen, V., Goutx, M., Prieur, L., and Dolan, J. R.: Short-scale temporal variability of physical, biological and biogeochemical processes in the NW Mediterranean Sea: an introduction, Biogeosciences Discuss., 5, 5233-5251, 2008, http://www.biogeosciences-discuss.net/5/5233/2008/.

25 Bamstedt, U., Gifford, D. J., Irigoien, X., Atkinson, A., and Roman, M.: Feeding, in Zooplankton Methodology Manual, Academic Press, 297-399, 2000. 
Dam, H. G., Roman, M. R., and Youngbluth, M. J.: Downward export of repiratory carbon and dissolved inorganic nitrogen by diel-migrant mesozooplankton at the JGOFS Bermuda time-series station, Deep-Sea Fres. Ptl, 42, 1187-1197, 1995.

Ikeda, T., Torres, J. J., Hernandez-Leon, S., and Geiger, S. P.: Metabolism, in Zooplankton Methodology Manual, Academic Press, 455-532, 2000.

Kleppel, G. S., Willbanks, L., and Pieper, R. E.: Diel variation in body carotenoid content and feeding activity in marine zooplankton assemblages, J. Plank. Res., 7, 569-580, 1985.

Lombard, F., Sciandra, A., and Gorsky, G.: Influence of body mass, food concentration, temperature and filtering activity on the oxygen uptake of the appendicularian Oikopleura dioica, Mar. Ecol. Prog. Ser., 301, 149-158, 2005.

Longhurst, A. R. and Harrison, W. G.: The biological pump: Profiles of plankton production and consumption in the upper ocean, Prog. Oceang., 22, 47-123, 1989.

Madin, L. P., Horgan, E. F., and Steinberg, D. K.: Zooplankton at the Bermuda Atlantic Timeseries Study (BATS) station: diel, seasonal and interannual variation in biomass, 1994-1998, Deep-Sea Res. pt., 2(48), 2063-2082, 2001.

Marty, J. C., Goutx, M., Guigue, C., Leblond, N., and Raimbault, P.: Short-term changes in particulate fluxes measured by drifting sediment traps during end summer oligotrophic regime in the NW Mediterranean Sea, Biogeosciences Discuss., 6, 575-606, 2009, http://www.biogeosciences-discuss.net/6/575/2009/.

20 Mayzaud, P.: Respiration and nitrogen excretion of zooplankton, II. Studies of the metabolism of starved animals, Mar. Biol., 21, 19-28, 1973.

Mayzaud, P., Boutoute, M., Gasparini, S., and Mousseau, L.: Respiration in marine zooplankton - the otheer side of the coin: $\mathrm{CO}_{2}$ production, Limnol. Oceanogr., 50, 291-298, 2005.

Mayzaud, P. and Conover, R. J.: O:N ratio as a tool to describe zooplankton metabolism, Mar. Ecol. Progr. Ser., 45, 289-302, 1988.

Raybaud, V., Nival, P., Mousseau, L., Gubanova, A., Altukhov, D., Khvorov, S., Ibanez, I., and Andersen, V.: Short term changes in zooplankton community during the summer-autumn transition in the open NW Mediterranean Sea: species composition, abundance and diversity, Biogeosciences, 5, 2237-2278, 2008,

30 http://www.biogeosciences.net/5/2237/2008/.

Raymont, J. E. G. and Conover, R. J.: Further investigations on the carbohydrate content of marine zooplankton, Limnol. Oceanogr., 6, 154-164, 1961.

Steinberg, D. K., Carlson, C. A., Bates, N. R., Goldthwait, S. A., Madin, L. P., and Michaels, A.

1009

F.: Zooplankton vertical migration and the active transport of dissolved organic and inorganic carbon in the Sargasso Sea, Deep-Sea Res. pt., 1(47), 137-158, 2000.

Stewart, G., Cochran, J. K., Miquel, J. C., Masqué, P., Szlosek, J., Rodriguez y Baena, A. M., Fowler, S. W., Gasser, B., and and Hirschberg, D. J.: Comparing POC export from $5234^{\mathrm{Th}} / 238 \mathrm{U}$ and $210 \mathrm{PO} / 210 \mathrm{~PB}$ disequilibria with estimates from sediment traps in the northwest Mediterranean, Deep-Sea Res. pt., 1(54), 1549-1570, 2007.

Turner, J. T.: Zooplankton fecal pellets, marine snow and sinking phytoplankton blooms, Aquat. Microb. Ecol., 27, 57-102, 2002. 
Table 1. Species determination of respiratory quotient (RQ) and metabolic quotient (MQ) during leg 1 and leg 2. sd: standard deviation; $\mathrm{Nb}$ : number of experiments run during the leg; To: Total number of organisms put in experimentation.

\begin{tabular}{|c|c|c|c|c|c|c|c|c|c|c|c|c|c|c|c|c|}
\hline & \multicolumn{6}{|c|}{ Leg 1} & \multicolumn{6}{|c|}{ Leg 2} & \multicolumn{4}{|c|}{ Both legs } \\
\hline & $\mathrm{Nb}$ & To & $\mathrm{RQ}$ & sd & MQ & sd & $\mathrm{Nb}$ & To & $\mathrm{RQ}$ & sd & $M Q$ & sd & $\mathrm{RQ}$ & $\mathrm{sd}$ & $M Q$ & sd \\
\hline Neocalanus gracilis & 19 & 168 & 1.21 & 0.12 & 13.96 & 5.93 & 8 & 84 & 1.37 & 0.33 & 9.42 & 1.62 & 1.26 & 0.22 & 12.10 & 5.47 \\
\hline Pleuro & na & na & na & na & na & na & 7 & 82 & 1.39 & 0.24 & 8.67 & 3.14 & 1.39 & 0.24 & 8.67 & 3.14 \\
\hline Eucha & na & na & na & na & na & na & 6 & 49 & 1.41 & 0.42 & 12.79 & 2.55 & 1.41 & 0.42 & 12.79 & 2.55 \\
\hline Meganyctiphanes norvegica & 17 & 30 & 1.00 & 0.14 & 14.72 & 4.72 & 14 & 29 & 1.14 & 0.11 & 18.13 & 3.93 & 1.06 & 0.14 & 16.27 & 4.56 \\
\hline Thysanopoda sp. & 4 & 10 & 1.14 & 0.35 & 20.99 & 8.82 & na & na & na & na & na & na & 1.14 & 0.35 & 20.99 & 8.82 \\
\hline Vibilia armata & 7 & 31 & 1.08 & 0.32 & 7.30 & 3.43 & 2 & 12 & 0.67 & na & 11.12 & & 0.97 & 0.34 & 8.02 & 3.31 \\
\hline Cavolinia inflexa & 16 & 73 & 1.13 & 0.18 & 15.76 & 6.05 & 8 & 55 & 0.97 & 0.24 & 17.66 & 3.35 & 1.07 & 0.21 & 16.40 & 5.21 \\
\hline Clio pyramidata & 9 & 17 & 1.04 & 0.40 & 12.45 & 4.52 & 7 & 14 & 1.34 & 0.50 & 6.85 & 2.37 & 1.16 & 0.46 & 9.59 & 4.72 \\
\hline Styliola & 4 & 12 & 1.23 & 1.16 & 10.60 & 9.59 & na & na & na & na & na & na & 1.23 & 1.16 & 10.60 & 9.59 \\
\hline Cymbuli & 10 & 12 & 0.96 & 0.40 & na & na & 2 & 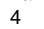 & 1.00 & na & na & na & 0.97 & 0.47 & na & na \\
\hline Chelophyes appendiculata & 9 & 16 & 0.50 & 0.33 & 7.95 & 2.50 & 6 & 16 & 1.13 & 0.37 & 9.87 & 5.48 & 0.73 & 0.45 & 8.79 & 4.21 \\
\hline Sagitta sp. & 5 & 16 & 2.25 & 0.65 & 9.80 & 4.29 & 5 & 13 & 1.24 & 0.12 & & & 1.61 & 0.70 & 9.80 & 4.29 \\
\hline
\end{tabular}

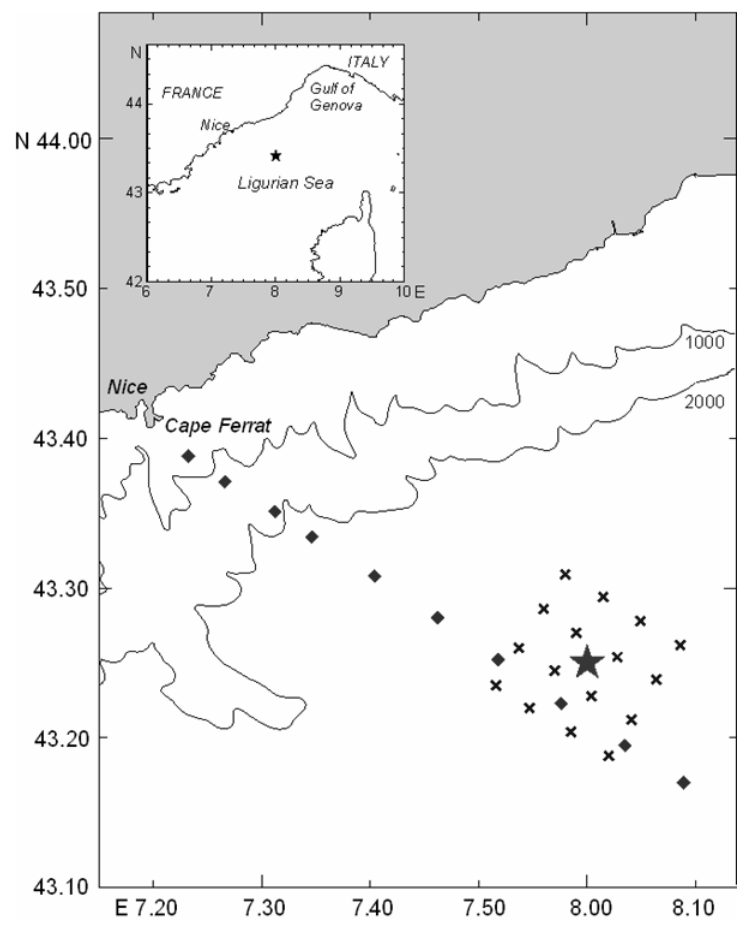

Fig. 1. Map of the sampling site $(\star)$ and of the transect performed at the beginning of the sampling period to determine the sampling site. 

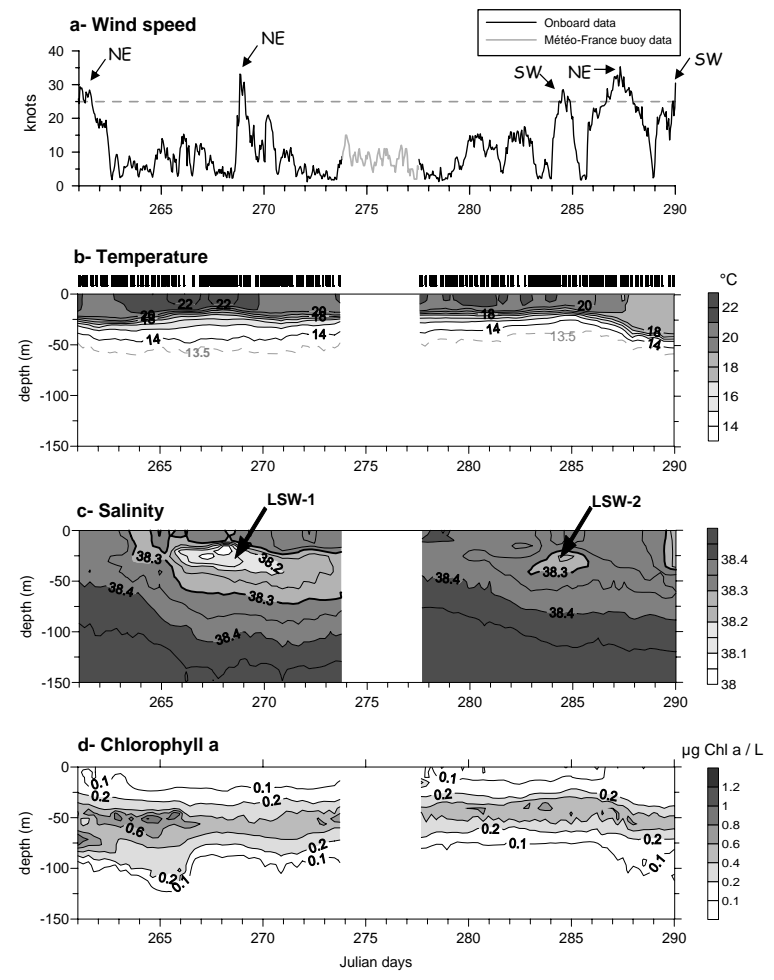

Fig. 2. Time-series data of wind strength in knots (a), vertical distribution of temperature (b), salinity (c) and Chlorophyll-a biomass (d) during DYNAPROC 2 cruise.
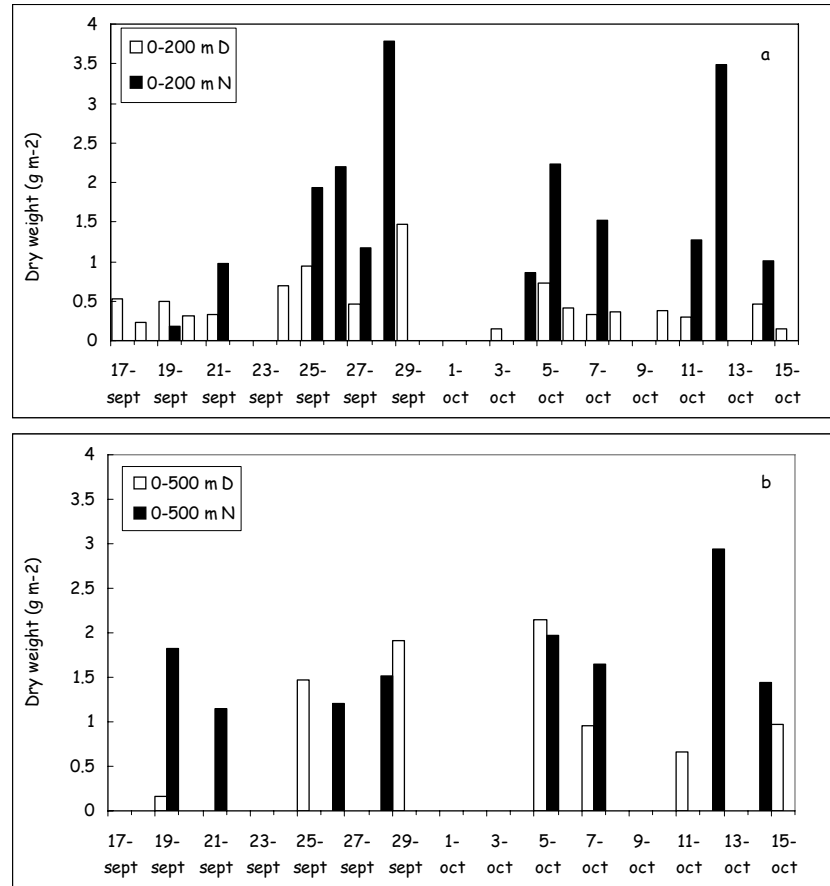

Fig. 3. Depth integrated biomass over 0-200 m (a) and 0-500 m (b) at day (D) and night (N). 


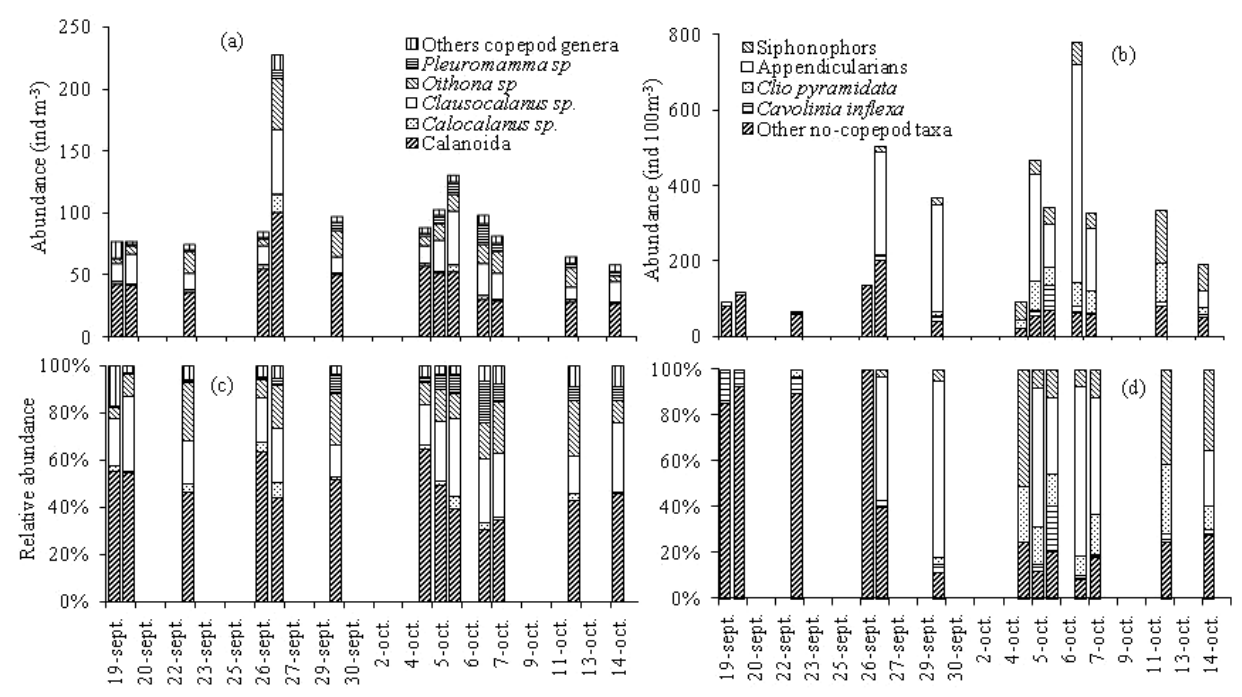

Fig. 4. Temporal variation of the abundance of (a) the dominant copepod genera and (b) noncopepod genera, and their respective relative contribution to the total assemblage (c, d). night sampling with the WPII.

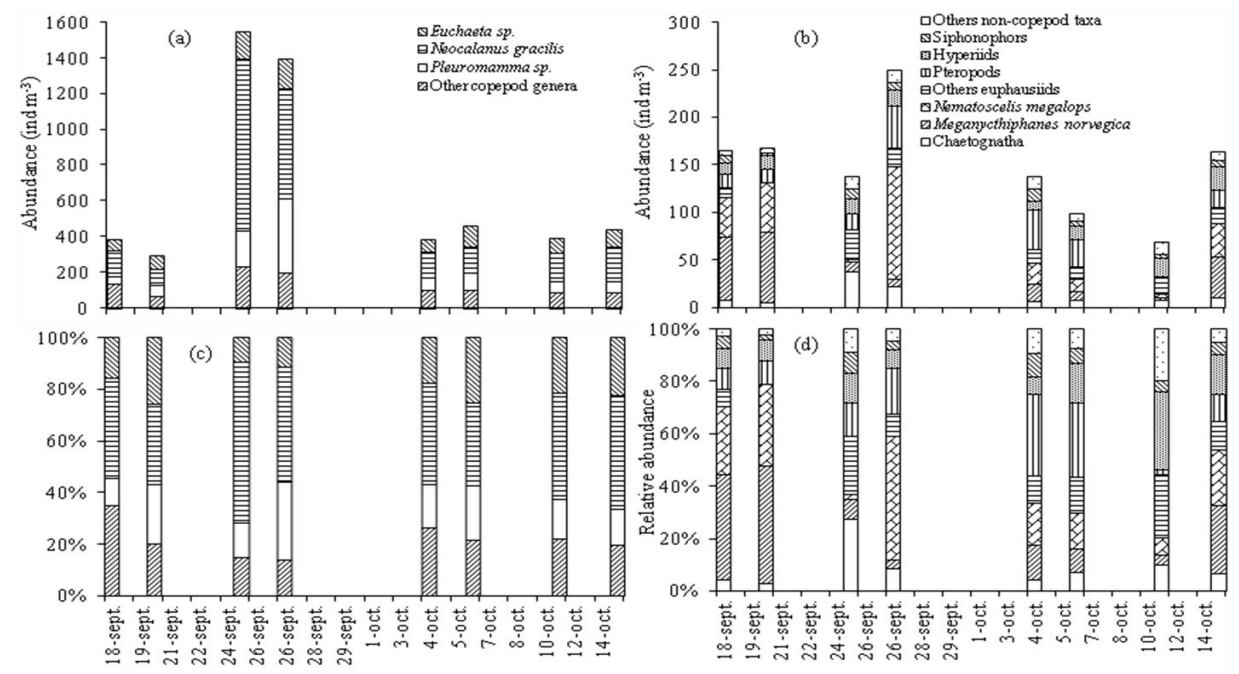

Fig. 5. Temporal variation of the abundance of (a) the dominant copepod genera and (b) noncopepod genera, and their respective relative contribution to the total assemblage (c, d). Night sampling with the multinet BIONESS. 

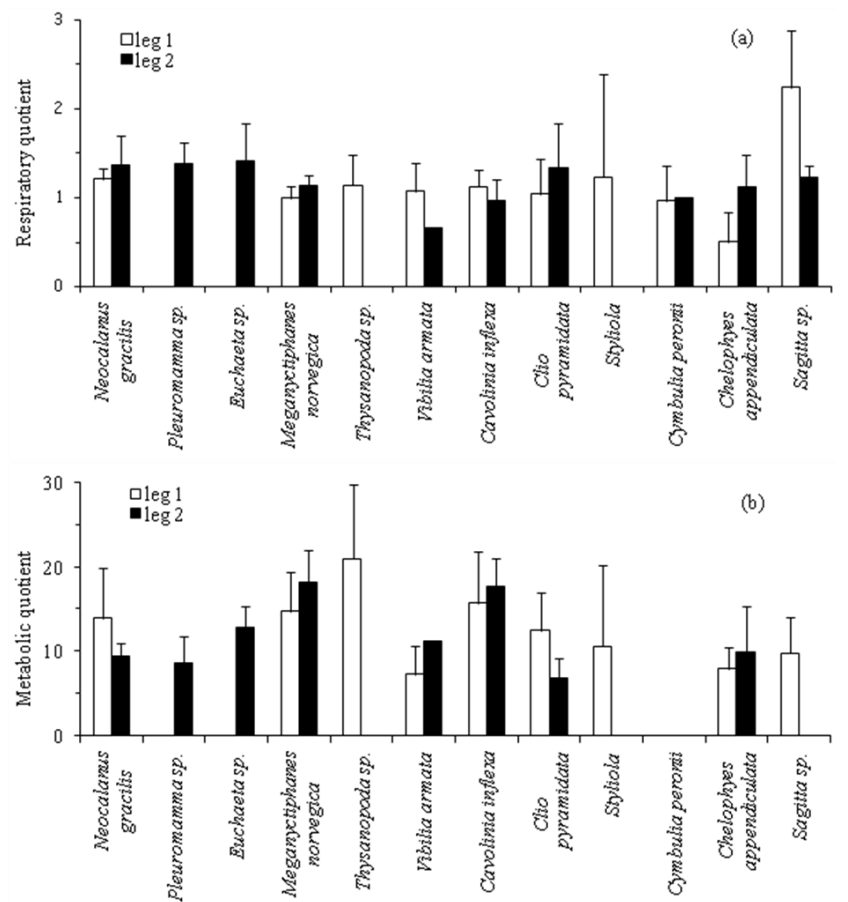

Fig. 6. Species-specific rate of estimates of respiratory (a) and metabolic (b) quotients; average of all estimates made during the whole sampling period.

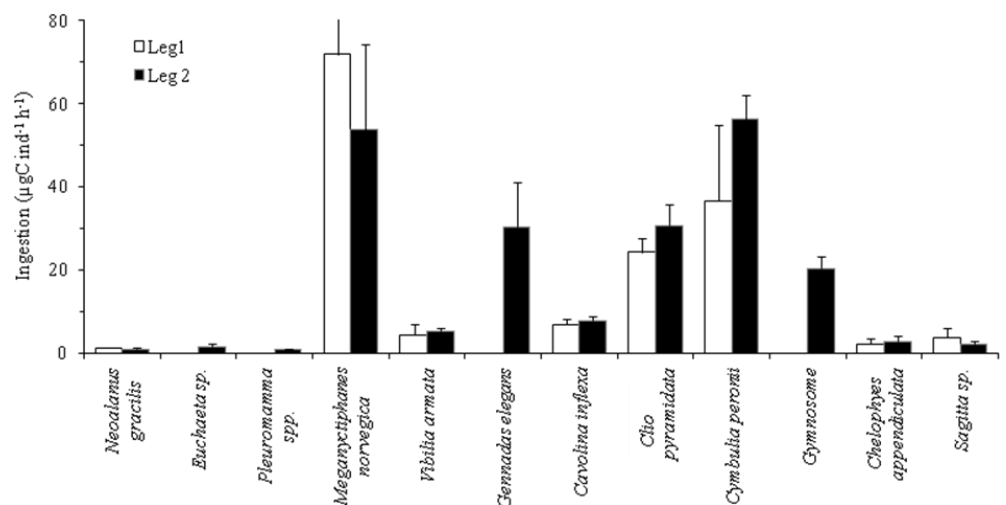

Fig. 7. Carbon ingestion $\left(\mu \mathrm{gC}\right.$ ind $\left.^{-1} \mathrm{~h}^{-1}\right)$ of the 12 genera sampled at the fixed station. Mean ingestion and standard deviation for Leg 1 and Leg 2 are represented. 


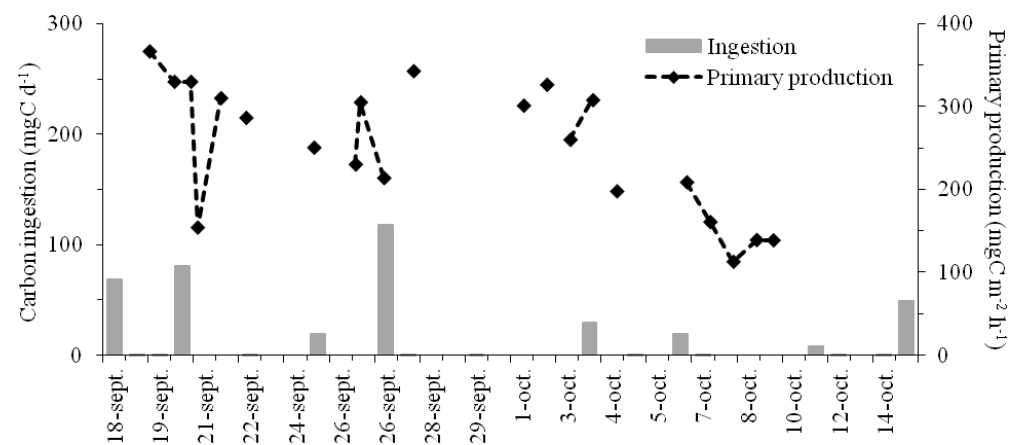

Fig. 8. Carbon ingestion of the zooplankton community (left axis) and integrated primary production (right axis) for the whole sampling period. 